\title{
Kömürlerin Kimyasal Özelliklerinin Kendiliğinden Yanma Yatkınlığı Üzerindeki Etkisinin Araştırılması
}

\author{
Özer ÖREN ${ }^{1}$, Cem ŞENSÖĞÜT ${ }^{* 1}$ \\ ${ }^{1}$ Dumlupınar Üniversitesi, Mühendislik Fakültesi, Maden Mühendisliği Bölümü, Kütahya
}

Geliş tarihi: 05.01.2016

Kabul tarihi: 11.05 .2016

\begin{abstract}
Özet
Yapılan bu çalışma ile 16 haftalık depolama süresi boyunca farklı koşullar altında depo edilen iki ayrı boyuttaki (35 ve 200 meş) kömür örneğinin kimyasal özelliklerinde (nem, uçucu madde, sabit karbon, kalori vs.) meydana gelen değişimlerin, kömürlerin kendiliğinden yanma yatkınlığı üzerindeki etkileri araştırılmıştır. Kömür örnekleri sırası ile azot tankı, derin dondurucu ve etüvde $-25,18$ ve $30^{\circ} \mathrm{C}$ sabit sıcaklıklar altında depo edilmiş̧ir. Kömürlerin kendiliğinden yanma yatkınlığının tespitinde "Kesişim Noktası Metodu" kullanılmış olup, deneyler sonucunda elde edilen yatkınlık indeksi ( $\mathrm{I}_{\mathrm{FCC}}$ ) değerleri ile kömür örneklerinin kimyasal özellikleri arasında anlamlı sonuçların olduğu ortaya konulmuştur.
\end{abstract}

Anahtar Kelimeler: Kömür, Kendiliğinden yanma, Kesişim noktası metodu, Kimyasal analiz

\section{Investigation of Chemical Properties of Coals on the Tendency of Spontaneous Combustion}

\begin{abstract}
Variations taking place in the chemical specifications (moisture, volatile matter, fixed carbon, calorific value etc.) of the coal samples with two different particle sizes (35 and 200 mesh) on the effect of the self ignition liability were examined. The coal samples in concern were preserved under different storing conditions for a period of 16 weeks. These samples of coal were upheld in different mediums such as nitrogen tank, deep freezer and oven under the pre-determined constant temperatures of $-25,18$ and $30^{\circ} \mathrm{C}$ respectively. In order to determine the tendency of spontaneous combustion for the coal samples, the method of crossing point was used. As a concluding remark, it may be stated that there is an expressive relation between the liability index $\left(\mathrm{I}_{\mathrm{FCC}}\right)$ and the chemical features of the coal samples.
\end{abstract}

Keywords: Coal, Spontaneous combustion, Crossing point method, Chemical analysis

* Yazışmaların yapılacağı yazar: Cem ŞENSÖĞÜT, Mühendislik Fakültesi, Maden Mühendisliği Bölümü, Kütahya.sensogut@dpu.edu.tr 


\section{GíRiș}

Kömürlerin kendiliğinden yanması, günümüz dünyasında hem yarattığı ekonomik kayıplar ele alındığında hem de meydana gelen ölümlü kazaların büyüklüğü düşünüldüğünde araştırmacılar için hala çok önemli ve çözümlenmesi gereken bir doğa olayı olarak karşımıza çıkmaktadır. Kömür havanın oksijeni ile temasa geçtiğinde, oksijen molekülleri kömüre ilk olarak fiziksel daha sonra ise kimyasal olarak adsorbe olmakta ve bu süreç kimyasal bir reaksiyon olarak sonuçlanmaktadır. $\mathrm{Bu}$ reaksiyon neticesinde açığa çıan 1Sı ortamdan uzaklaştırılamaz ise; biriken 1sı kömürün kendiliğinden yanmasına neden olmakta ve uygun şartlar sağlandığında açık alevli yangına dönüşebilmektedir. Kendiliğinden yanma olayı kömürün karmaşık yapısından dolayı birden fazla faktörün etkisinde gerçekleşen bir süreçtir. Kendiliğinden yanmayı etkileyen faktörler Çizelge 1'de görüldüğü üzere iç ve diş faktörler olarak ikiye ayrılmaktadır [1]. Bu faktörlerin kendiliğinden yanma ve kömür oksidasyonu üzerindeki etkileri farklı araştırmacılar tarafindan incelenmiş olup özellikle kömür özelliklerinin bu olay üzerindeki değişimleri yapılan çalışmaların merkezini oluşturmaktadır [2-8].

Yapılan bu çalışma ile kömür ve oksijen arasında gerçekleşen reaksiyonun minimuma indirilmesi ve laboratuvar ortamındaki en uygun depolama şartının ortaya konulması adına 3 farklı saklama koşulunda 16 hafta boyunca muhafaza edilen kömürlerin kendiliğinden yanma yatkınlık değişimleri gözlemlenmiştir. Kesişim Noktası Metodu (KNM) ile tutuşma sıcaklıkları ve yanma risk indeksleri belirlenmiş ve açığa çıkan sonuçlar irdelenmeye çalışılmıştır. Ayrıca, numunelerin süreç boyunca belirlenen kisa ve elementel analiz değerleri ile kendiliğinden yanmaya yatkınlık arasındaki ilişkiler araştırılmıştır.

\section{MATERYAL VE METOT}

Çalışma için kullanılan kömür örnekleri Garp Linyitleri İşletmesi Tunçbilek Bölgesi Y4 panosu açık ocaklarından temin edilmiştir. Kömür oksidasyonunu engellemek için alüminyum folyo ve streç film ile kaplanarak Dumlupınar Üniversitesi Maden Mühendisliği Laboratuvarlarına getirilen kömür örnekleri, burada 35 ve 200 meş tane boyutlarına indirgenmiştir. Daha sonra bu kömür örnekleri kilitli poşetlerin içerisine konulmuş ve 8 hafta boyunca azot tankı (at), derin dondurucu (dd) ve etüv (et) ortamında depo edilmiştir.

Oksidasyonun ve kömür özelliklerinin net etkilerini görebilmek adına, poşetlerden çıkarılan kömürler tepsilerde aynı depolama koşulları sabit kalacak şekilde 8 hafta daha depo edilmiştir. Depolama sicaklıkları sirası ile azot tankı, derin dondurucu ve etüv için $-25,18$ ve $30^{\circ} \mathrm{C}$ olarak belirlenmiştir. 16 haftalık süreç boyunca kömürlerin her iki haftada bir kimyasal analizleri gerçekleştirilirken aynı dönemde kömürlerin kendiliğinden yanma yatkınlıkları da tespit edilmiştir [9]. KNM deneyleri için Şekil 1'de gösterilen düzenek yardımı ile gerçekleştirilmiştir. Buna göre; kömür reaktörüne konulan yaklaşık 30 gr ağırlığındaki numuneler, yaklaşık 5 saat boyunca $100 \mathrm{cc} / \mathrm{dk}$ hava akışına maruz kalacak şekilde doğrusal olarak isıtılan firın içerisine yerleştirilmiş ve gerek firın gerekse de numune sıcaklığı 10 dakikada bir kaydedilmiştir. Söz konusu firın $18^{\circ} \mathrm{C}$ 'de sabitlenen ortam sıcaklığından itibaren $0,5^{\circ} \mathrm{C}^{\prime}$ lik artışlar ile $300^{\circ} \mathrm{C}$ 'ye kadar 1 sıtılmıştır. Deney esnasında, kömürlerin 110 ve $220^{\circ} \mathrm{C}$ sıcaklığa ulaştıkları süre dakika cinsinden kaydedilirken aynı zamanda kömürün firın sıcaklığını kestiği noktadaki sıcaklık değeri yani tutuşma sıcaklığı da yapılan deneysel gözlemlerde belirlenmiştir. Kömürlerin ortalama sıcaklık artışı (OSA) ve kendiliğinden yanma indekslerinin $\left(\mathrm{I}_{\mathrm{FCC}}\right)$ hesaplamasında Eşitlik (1) ve Eşitlik (2)'deki denklemlerden yararlanılmıştır.

Ort. Sic. Artışı $(O S A)=\frac{110}{t_{2}-t_{1}}$

$I_{(F C C)}=\frac{\text { Ort. Sic. Artıșl }(O S A)}{\text { Tutușma Sıcaklığ } l}$ 
Çizelge 1. Kendiliğinden yanmayı etkileyen faktörler

\begin{tabular}{|c|c|c|c|}
\hline \multirow[b]{2}{*}{ Kömür özellikleri } & \multirow[b]{2}{*}{ Jeolojik özellikler } & \multicolumn{2}{|c|}{ Diş (ekzojen) faktörler } \\
\hline & & $\begin{array}{c}\text { Atmosferik } \\
\text { koşullar }\end{array}$ & $\begin{array}{c}\text { Madencilik ile ilgili } \\
\text { faktörler }\end{array}$ \\
\hline $\begin{array}{ll} & \text { Kömürleşme } \\
& \text { derecesi } \\
\text { - } & \text { Petrografik yapı } \\
\text { - } & \text { Nem içeriği } \\
\text { - } & \text { Mineral madde } \\
& \text { içeriği } \\
\text { - } & \text { Tane boyutu } \\
\text { - } & \text { Pirit içeriği } \\
\text { - } & \text { Fiziksel } \\
& \text { özellikler } \\
\text { - } & \text { Bakteriler }\end{array}$ & $\begin{array}{ll}\text { - } & \text { Damar } \\
& \text { kalınlığ } \\
\text { - } & \text { Damar } \\
& \text { eğimi } \\
\text { - } & \text { Göçme } \\
& \text { özelliği } \\
\text { - } & \text { Fay ve } \\
& \text { arızalar } \\
\text { - } & \text { Derinlik } \\
\text { - } & \text { Jeotermik } \\
\text { gradyan }\end{array}$ & $\begin{array}{ll}- & \text { Sicaklık } \\
\text { - } & \text { Nem } \\
\text { - } & \text { Oksijen } \\
& \text { derişimi }\end{array}$ & $\begin{array}{ll}\text { - } & \text { Üretim yöntemi } \\
\text { - } & \text { İlerleme hızı } \\
\text { - } & \text { Topuk koşulları } \\
\text { - } & \text { Tavan koşulları } \\
\text { - } & \text { Tabanyolu } \\
& \text { koşulları } \\
\text { - } & \text { Hava kaçakları } \\
\text { - } & \text { Kömür kayıpları } \\
\text { - Çalışılmış sahalar } \\
\text { - } & \text { Dolgu } \\
\text { - Havalandırma } \\
& \text { basıncı } \\
\text { - } & \text { Hava nemliliği }\end{array}$ \\
\hline
\end{tabular}

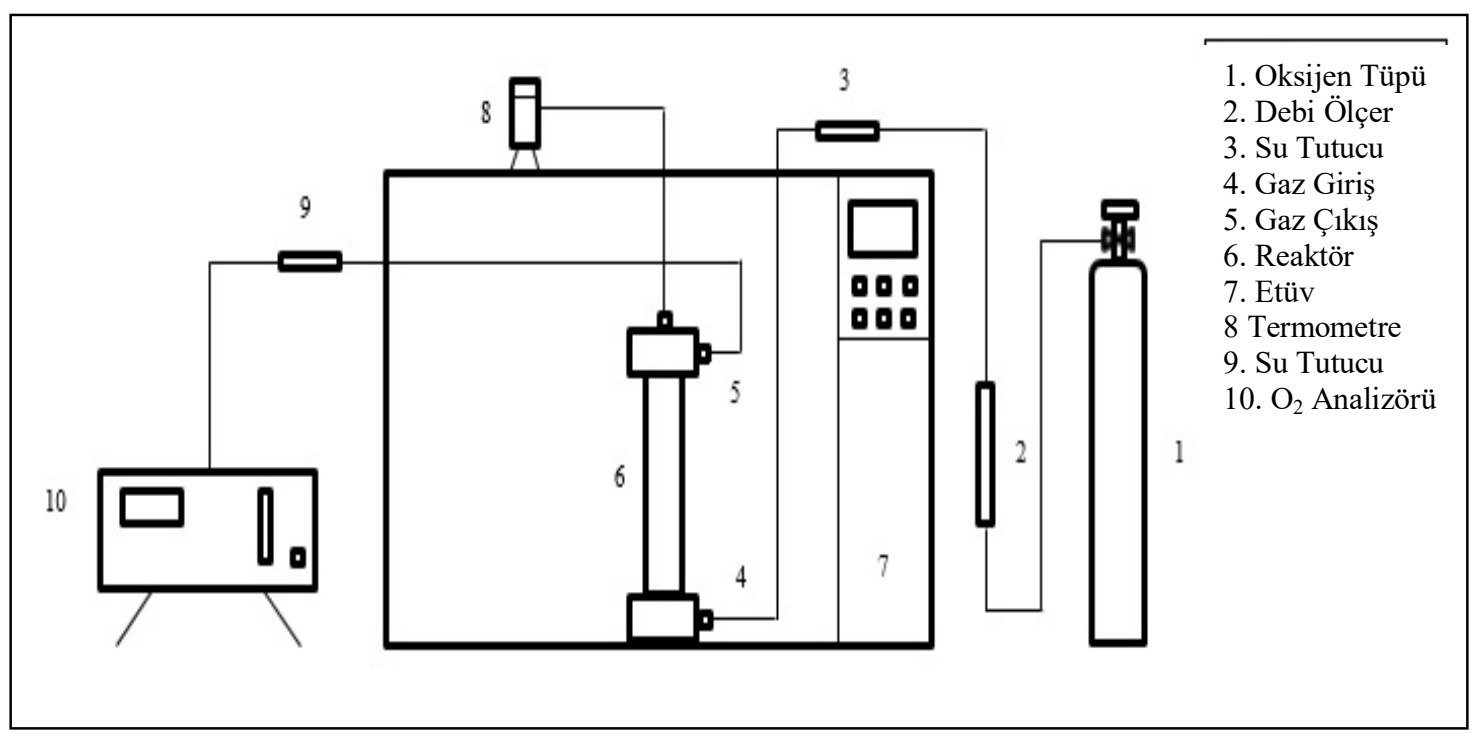

Şekil 1. Kendiliğinden yanma deney düzeneği

\section{DENEYSEL CALIŞMALAR}

Kömür örneklerinin kısa ve elementel analizi Garp Linyitleri İşletmesi Kömür Analiz Laboratuvarında gerçekleştirilmiş̧ir. 35 ve 200 meş tane boyutuna sahip tüvenan kömür örneklerine ait kisa ve elementel analiz değerleri Çizelge 2 ve Çizelge 3'te verilmiştir.
Yapılan değerlendirmelerde orijinal kömüre ait analiz değerleri kullanılırken; tüm kömür örneklerine ait 16 haftalık süreçteki kısa ve elementel analiz verileri Çizelge 4 ve Çizelge 5 'te gösterilmiştir. Ayrıca kendiliğinden yanma yatkınlık deneylerinde elde edilen sonuçlar da Çizelge 6'da belirtilmiştir. 
Çizelge 2. 200 meş boyuta sahip tüvenan kömür örneğinin kısa ve elementel analiz değerleri

\begin{tabular}{|c|c|c|c|}
\hline Analizler & $\begin{array}{l}\text { Orijinal } \\
\text { Kömür }\end{array}$ & $\begin{array}{c}\text { Kuru } \\
\text { Kömür }\end{array}$ & Metot \\
\hline Nem $(\%)$ & 11,69 & & TS 690 ISO 589 Metot C \\
\hline Kül (\%) & 8,68 & 9,83 & ASTM D 7582 \\
\hline Uçucu madde (\%) & 37,82 & 42,83 & ASTM D 7582 \\
\hline Sabit karbon (\%) & 41,81 & 47,34 & Hesap \\
\hline Toplam (\%) & 100 & 100 & Hesap \\
\hline Kükürt (\%) & 1,6 & 1,81 & ASTM D 4239 \\
\hline $\begin{array}{l}\text { Alt kalorifik değer } \\
(\mathrm{kcal} / \mathrm{kg})\end{array}$ & 5475 & 6273 & TS EN ISO 1928 \\
\hline $\begin{array}{l}\text { Üst kalorifik değer } \\
(\mathrm{kcal} / \mathrm{kg})\end{array}$ & 5753 & 6515 & ASTM D 5865 \\
\hline
\end{tabular}

\begin{tabular}{|l|c|c|c|}
\hline Hidrojen (\%) & 5,46 & 4,7 & \multirow{2}{*}{ ASTM D 5373 } \\
\cline { 1 - 2 } Karbon (\%) & 59,09 & 66,91 & \\
\hline Nitrojen (\%) & 1,48 & 1,67 & Hesap \\
\hline Oksijen (\%) & 23,69 & 15,07 & \\
\hline
\end{tabular}

Çizelge 3. 35 meş boyuta sahip tüvenan kömür örneğinin kısa ve elementel analiz değerleri

\begin{tabular}{|l|c|c|c|}
\hline Analizler & $\begin{array}{c}\text { Orijinal } \\
\text { Kömür }\end{array}$ & $\begin{array}{c}\text { Kuru } \\
\text { Kömür }\end{array}$ & Metot \\
\hline Nem (\%) & 13,33 & & TS 690 ISO 589 Metot C \\
\hline Kül (\%) & 8,12 & 9,37 & ASTM D 7582 \\
\hline Uçucu madde (\%) & 37,96 & 43,8 & ASTM D 7582 \\
\hline Sabit karbon (\%) & 40,59 & 46,83 & Hesap \\
\hline Toplam (\%) & 100 & 100 & Hesap \\
\hline
\end{tabular}

\begin{tabular}{|c|c|c|c|}
\hline Kükürt (\%) & 1,52 & 1,75 & ASTM D 4239 \\
\hline $\begin{array}{l}\text { Alt kalorifik değer } \\
(\mathrm{kcal} / \mathrm{kg})\end{array}$ & 5372 & 6283 & TS EN ISO 1928 \\
\hline $\begin{array}{l}\text { Üst kalorifik değer } \\
\text { (kcal/kg) }\end{array}$ & 5658 & 6528 & ASTM D 5865 \\
\hline
\end{tabular}

\begin{tabular}{|l|c|c|c|}
\hline Hidrojen (\%) & 5,71 & 4,87 & \multirow{2}{*}{ ASTM D 5373 } \\
\hline Karbon (\%) & 58,67 & 67,7 & \\
\hline Nitrojen (\%) & 1,41 & 1,63 & Hesap \\
\hline Oksijen (\%) & 24,57 & 14,69 & \\
\hline
\end{tabular}


Çizelge 4. 200 meş boyutuna sahip kömür örneğine ait 16 haftalık süreçte farklı depo şartları altındaki kısa ve elementel analiz değerleri

\begin{tabular}{|c|c|c|c|c|c|c|c|c|c|c|c|c|c|c|c|c|c|c|c|c|}
\hline$\frac{\frac{0}{\bar{v}}}{0} \frac{0}{0}$ & 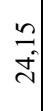 & 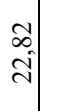 & خे & 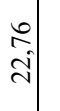 & 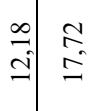 & \begin{tabular}{c}
$c$ \\
\hdashline
\end{tabular} & $\begin{array}{l}8 \\
: \\
-1\end{array}$ & $\begin{array}{l}\text { ñ } \\
\text { הี }\end{array}$ & 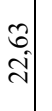 & 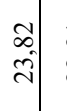 & $\begin{array}{ll}\bar{a} & \stackrel{0}{2} \\
\text { ปे }\end{array}$ & ה̂̀. & 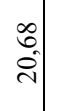 & 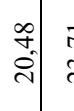 & $\begin{array}{ll}\vec{\lambda} & \bar{\imath} \\
\hat{\imath} & \bar{\imath}\end{array}$ & जे| & $\underset{\mathrm{n}}{\overrightarrow{0}}$ & 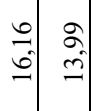 & $\stackrel{0}{=}$ & $\begin{array}{l}\tilde{\delta} \\
\stackrel{-}{=}\end{array}$ \\
\hline$\frac{1}{8}$ & for. & $\stackrel{f}{=}$ & f & $\vec{F}$ & $\stackrel{\substack{\infty \\
\hdashline}}{\rightarrow}=$ & 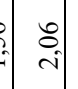 & શิ & $\stackrel{f}{f}+$ & and & $\vec{n}$ & 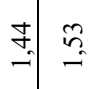 & $\overrightarrow{=}$ & $\stackrel{n}{\sim}$ & $\stackrel{\infty}{-}$ & 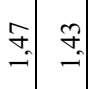 & 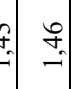 & $\stackrel{q}{-}$ & $n=$ & तี & $\stackrel{\substack{\infty \\
-}}{-}$ \\
\hline 爮 & $\begin{array}{l}\hat{b} \\
\infty \\
i\end{array} \mid$ & $\begin{array}{c}\hat{\infty} \\
\infty \\
\infty \\
i \\
0\end{array}$ & $\begin{array}{c}\infty \\
\overrightarrow{0} \\
i \\
i n\end{array}$ & ริ. & 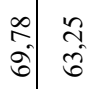 & \begin{tabular}{|l|l|} 
\\
$\vdots$ \\
0 \\
0 \\
0 \\
0
\end{tabular} & $\begin{array}{l}\stackrel{0}{1} \\
\hat{b}\end{array}$ & $\begin{array}{l}\text { f. } \\
\text { s. }\end{array}$ & 훌 & 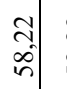 & $\begin{array}{l}\text { ते } \\
\text { in } \\
\text { in }\end{array}$ & $\frac{0}{6}$ & $\begin{array}{l}\tilde{n} \\
\vdots \\
0\end{array}$ & $\begin{array}{l}\infty \\
0 \\
-0\end{array}$ & 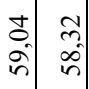 & 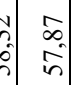 & $\begin{array}{c}r \\
\substack{0 \\
\infty \\
n \\
n}\end{array}$ & 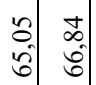 & 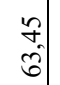 & $\begin{array}{l}\bar{n} \\
\dot{0} \\
\dot{0}\end{array}$ \\
\hline 递 & $\begin{array}{c}\infty \\
\dot{1} \\
\dot{n}\end{array}$ & $\begin{array}{c}0 \\
+ \\
n\end{array}$ & $\begin{array}{c}\text { ?. } \\
\text { nी }\end{array}$ & $\vec{\imath}$ & 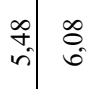 & 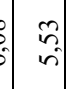 & $\begin{array}{l}8 \\
\dot{0}\end{array}$ & $\begin{array}{c}f \\
\dot{f}\end{array}$ & $\begin{array}{c}7 \\
7 \\
n\end{array}$ & $\begin{array}{l}\infty \\
\infty \\
n \\
n\end{array}$ & $\begin{array}{ll}2 & n \\
n & \approx\end{array}$ & ㄷ․ & $\begin{array}{c}\tilde{b} \\
i \\
-1\end{array}$ & $\begin{array}{l}5 \\
0 \\
i\end{array}$ & \begin{tabular}{cc|c}
0 & 0 \\
1 \\
$n$
\end{tabular} \mid & 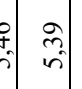 & $\begin{array}{l}\tilde{7} \\
i\end{array}$ & $\begin{array}{ccc}0 & 0 \\
0 & 0 \\
\end{array}$ & $\begin{array}{l}\text { oे } \\
\text { in }\end{array}$ & $\stackrel{\substack{f \\
f}}{f}$ \\
\hline 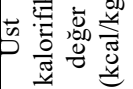 & $\begin{array}{l}n \\
\tilde{n}\end{array}$ & 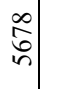 & $\stackrel{m}{n}$ & 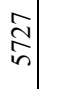 & 点 & $\begin{array}{c}c \\
\vdots \\
i n\end{array}$ & $\begin{array}{l}0 \\
\stackrel{0}{n} \\
\end{array}$ & 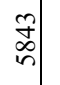 & 常 & $\begin{array}{l}\text { ta } \\
\text { in }\end{array}$ & \begin{tabular}{l|l}
$\infty$ & 0 \\
0 & $\infty$ \\
in & in
\end{tabular} & $\hat{n}$ & $\begin{array}{l}t \\
\text { in } \\
\text { in }\end{array}$ & $\begin{array}{l}a \\
\infty \\
i\end{array}$ & 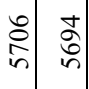 & 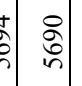 & $\begin{array}{l}\tilde{n} \\
\hat{n}\end{array}$ & 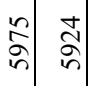 & $\overrightarrow{\widehat{b}}$ & స్ర \\
\hline 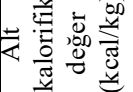 & 吕 & ڤ్ & 触 & 热 & \begin{tabular}{l|l}
$\substack{f \\
m}$ & 7 \\
$m$
\end{tabular} & 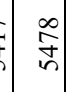 & $\overrightarrow{\bar{a}}$ & $\begin{array}{l}n \\
\tilde{b} \\
n\end{array}$ & 余 & $\frac{7}{7}$ & 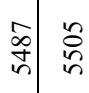 & 它 & 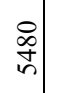 & 点 & $\begin{array}{c}\text { ì } \\
\stackrel{7}{n} \\
\text { n }\end{array}$ & 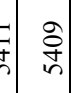 & 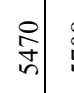 & 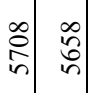 & $\begin{array}{l}\stackrel{\vdots}{n} \\
\hat{n}\end{array}$ & : \\
\hline 8 & $\underset{-1}{\sigma}$ & $\stackrel{:}{-}$ & : & $\stackrel{S}{-}$ & $\stackrel{5}{-5}=$ & 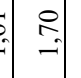 & $\underset{-1}{-0}$ & $\stackrel{\cong}{=}$ & . & : & : & 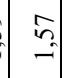 & $\stackrel{5}{-}$ & $\tilde{\sigma}$ & $\begin{array}{c}5 \\
-\end{array}$ & \begin{tabular}{c}
0 \\
\hdashline \\
\hdashline
\end{tabular} & $\stackrel{n}{\sim}$ & $\tilde{n}=$ & $:$ & $\stackrel{-}{-}$ \\
\hline 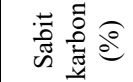 & $\stackrel{\vec{f}}{\vec{\gamma}}$ & $\begin{array}{l}\text { fे } \\
\text { mे. }\end{array}$ & $\begin{array}{l}: \\
\vdots \\
\square\end{array}$ & $\begin{array}{l}\text { ț } \\
\dot{q}\end{array}$ & 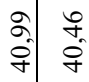 & 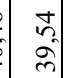 & $\begin{array}{l}0 \\
\stackrel{n}{7} \\
\overrightarrow{7}\end{array}$ & $\begin{array}{l}\stackrel{0}{\circ} \\
\stackrel{y}{f}\end{array}$ & हे. & $\begin{array}{c}0 \\
\vdots \\
0 \\
+\end{array}$ & $\begin{array}{ll}0 & \vec{b} \\
\vec{f} & \overrightarrow{7}\end{array}$ & $\begin{array}{c}n \\
0 \\
q\end{array}$ & $\overrightarrow{\vec{q}}$ & $\begin{array}{ll}i & 0 \\
\overrightarrow{7}\end{array}$ & $\begin{array}{cc}\vec{c} & \pm \\
\vec{f} \\
\vec{f}\end{array}$ & 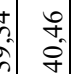 & $\begin{array}{l}\text { aे } \\
\dot{q}\end{array}$ & 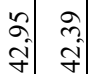 & $\begin{array}{l}\tilde{\sigma} \\
\overrightarrow{7}\end{array}$ & $\begin{array}{l}0 \\
n \\
f \\
f\end{array}$ \\
\hline $\begin{array}{ll}\bar{z} \\
\bar{z} \\
\vec{c}\end{array}$ & $\begin{array}{l}\approx \\
\hat{m}\end{array}$ & $\begin{array}{c}\mathbb{1} \\
\infty \\
\infty \\
m\end{array}$ & 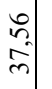 & ç & 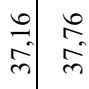 & $\begin{array}{l}n \\
0 \\
\infty \\
\infty\end{array}$ & $\begin{array}{l}\hat{n} \\
\hat{m}\end{array}$ & $\begin{array}{c}m \\
\infty \\
\infty \\
m\end{array}$ & $\begin{array}{c}2 \\
\cdots \\
\infty \\
\infty\end{array}$ & 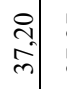 & 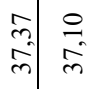 & $\begin{array}{c}8 \\
\infty \\
\infty \\
m\end{array}$ & $\begin{array}{c}\tilde{m} \\
\infty \\
\infty \\
m\end{array}$ & $\begin{array}{c}q \\
\dot{m} \\
\end{array}$ & \begin{tabular}{c|c|}
$\infty$ & $\hat{1}$ \\
$\infty$ & 0 \\
$\hat{m}$ & $\infty$ \\
$m$
\end{tabular} & $=0$ & $\begin{array}{l}\cong \\
\stackrel{2}{2}\end{array}$ & 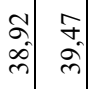 & $\begin{array}{l}2 \\
\hat{q}\end{array}$ & $\begin{array}{l}\tilde{0} \\
0 \\
0 \\
\end{array}$ \\
\hline$\overline{\mathrm{E}} \mathrm{\varrho}$ & $\begin{array}{l}0 \\
0 \\
\infty\end{array}$ & $\begin{array}{l}0 \\
0 \\
\vdots \\
\vdots\end{array}$ & $\begin{array}{c}\infty \\
\vdots \\
\vdots \\
2\end{array}$ & ڤે. & \begin{tabular}{c}
0 \\
$\vdots$ \\
\hdashline
\end{tabular} & $\alpha$ & : & 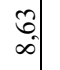 & 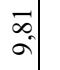 & $\begin{array}{l}\infty \\
2 \\
\sigma^{2}\end{array}$ & $\begin{array}{c}f \\
a \\
a\end{array}$ & $\frac{2}{a}$ & $\begin{array}{l}q \\
\sigma \\
\sigma\end{array}$ & ळ. & $\begin{array}{lll}\hat{\delta} & \ddots \\
\infty & \ddots\end{array}$ & 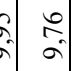 & 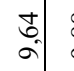 & \begin{tabular}{c|c|c}
$\infty$ & $\vec{y}$ \\
$\infty$ & 0 \\
$\infty$ & 0
\end{tabular} & $\begin{array}{l}\infty \\
\stackrel{0}{0} \\
\stackrel{2}{0}\end{array}$ & $\begin{array}{l}\infty \\
\stackrel{0}{0}\end{array}$ \\
\hline $\bar{\Xi}$ & $\begin{array}{l}0 \\
\stackrel{0}{-1} \\
-1\end{array}$ & 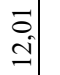 & 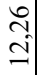 & $\begin{array}{l}\hat{s} \\
\dot{j}\end{array}$ & 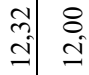 & $\stackrel{0}{=}$ & $\begin{array}{l}\infty \\
\infty \\
0 \\
0\end{array}$ & $\begin{array}{l} \pm \\
\stackrel{0}{0}\end{array}$ & $\stackrel{0}{=}$ & $\begin{array}{l}0 \\
\stackrel{0}{c} \\
\end{array}$ & 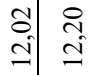 & $\begin{array}{l}\sim \\
\simeq \\
\simeq \\
\simeq\end{array}$ & 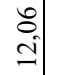 & $\begin{array}{ll}\stackrel{2}{=} & \\
= & \end{array}$ & $\begin{array}{ll}n \\
0 \\
= \\
= & = \\
= & =\end{array}$ & 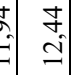 & $\begin{array}{l}\simeq \\
\simeq \\
\simeq\end{array}$ & 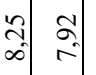 & $\begin{array}{l}8 \\
6 \\
6\end{array}$ & in \\
\hline 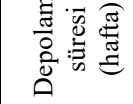 & $N$ & $\nabla$ & 0 & $\infty$ & $=\simeq$ & \pm & $=$ & & $\nabla$ & 6 & 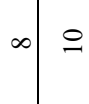 & $\simeq$ & \pm & \begin{tabular}{l|l}
0 & 0
\end{tabular} & $N \quad+$ & 50 & $\infty$ & $\approx \simeq$ & \pm & 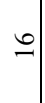 \\
\hline 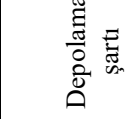 & & & & $\begin{array}{l}\text { 烝 } \\
0 \\
0\end{array}$ & & & & & & & & & & & & & & & & \\
\hline
\end{tabular}


Çizelge 5. 35 meş boyutuna sahip kömür örneğine ait 16 haftalık süreçte farklı depo şartları altındaki kısa ve elementel analiz değerleri

\begin{tabular}{|c|c|c|c|c|c|c|c|c|c|c|c|c|c|c|c|c|c|c|c|c|c|c|}
\hline$\frac{\overrightarrow{5}}{0}$ & $\begin{array}{l}\stackrel{7}{ \pm} \\
\stackrel{+}{d}\end{array}$ & $\begin{array}{l}\text { s. } \\
\text { ते }\end{array}$ & $\begin{array}{l}0 \\
\stackrel{0}{d} \\
\dot{d}\end{array}$ & 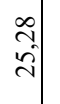 & $\begin{array}{l}\infty \\
\infty \\
\infty \\
\infty \\
-1\end{array}$ & $\stackrel{+}{2}$ & $\widehat{\hat{i}}$ & 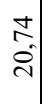 & ণ্ণ & $\begin{array}{l}+ \\
\text { iी }\end{array}$ & 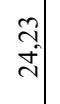 & $\begin{array}{l}8 \\
\dot{i}\end{array}$ & $\begin{array}{l}0 \\
\stackrel{0}{0} \\
0\end{array}$ & 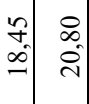 & 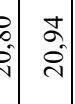 & $\mid \begin{array}{l}\infty \\
\infty \\
\sim \\
\sim\end{array}$ & త్ర & $\begin{array}{l}\stackrel{1}{d} \\
\dot{d}\end{array}$ & 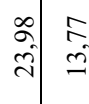 & $\left|\begin{array}{l}1 \\
q \\
6 \\
-6\end{array}\right|$ & $\begin{array}{l}\stackrel{\infty}{\infty} \\
-\infty \\
-\infty\end{array}$ & : \\
\hline 产 & 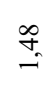 & $\underset{f}{f}$ & $\stackrel{+}{-}$ & $\stackrel{f}{q}=$ & $\stackrel{n}{n}$ & : & $\begin{array}{c}\tilde{c} \\
\text { î }\end{array}$ & $\stackrel{\infty}{\stackrel{\infty}{=}}$ & $\stackrel{n}{\rightarrow}$ & $\stackrel{\infty}{+}+$ & $\underset{f}{ \pm}$ & $\stackrel{f}{q}$ & 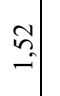 & $\begin{array}{lll}\vec{n} & \overrightarrow{0} \\
\rightarrow & i\end{array}$ & 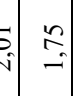 & $\stackrel{f}{-}$ & 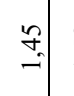 & $\stackrel{\tilde{n}}{\rightarrow}$ & $\stackrel{g}{=}$ & $\stackrel{n}{n}$ & 원 & $\stackrel{\infty}{-\infty}$ \\
\hline 2 & $\begin{array}{l}+ \\
\infty^{+} \\
n^{2}\end{array}$ & 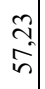 & 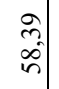 & 현 & 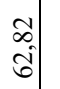 & $\begin{array}{l}\infty \\
n \\
\hat{b} \\
0\end{array}$ & $\begin{array}{l}2 \\
\stackrel{0}{0} \\
0\end{array}$ & $\begin{array}{l}\text { जa } \\
\vec{b}\end{array}$ & $\begin{array}{l}n \\
\infty \\
n\end{array}$ & $\begin{array}{l}\tilde{Z} \\
\infty \\
n \\
n\end{array}$ & $\begin{array}{l}\tilde{n} \\
\infty \\
0 \\
n\end{array} \mid$ & $\begin{array}{c}\vec{F} \\
\infty \\
i\end{array}$ & $\begin{array}{l}\stackrel{0}{0} \\
-0\end{array}$ & 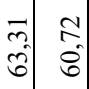 & \begin{tabular}{ll|}
0 & 8 \\
0 & 0 \\
0 & -1
\end{tabular} & 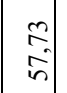 & $\begin{array}{l}\hat{A} \\
\infty \\
n\end{array}$ & $\begin{array}{l}8 \\
\infty \\
i n\end{array}$ & \begin{tabular}{c|c}
$t$ & 0 \\
$\infty$ & 0 \\
0 & 0 \\
$n$ & 0
\end{tabular} & $\begin{array}{l}0 \\
m \\
2 \\
6\end{array}$ & 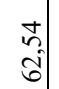 & \\
\hline 递 & 8 & $\begin{array}{l}0 \\
n \\
n\end{array}$ & ले & ch & กู & $\begin{array}{l}2 \\
0 \\
0 \\
0\end{array}$ & $\begin{array}{l}\Re \\
\hat{n}\end{array}$ & $\begin{array}{l}n \\
n \\
n\end{array}$ & $\begin{array}{l}\overrightarrow{6} \\
i\end{array}$ & $\begin{array}{l}\dot{n} \\
\dot{n} \\
n\end{array}$ & $\begin{array}{l}n \\
n\end{array}$ & $\begin{array}{c}\vec{F} \\
i\end{array}$ & ڤે. & \begin{tabular}{c|c}
$\begin{array}{c}0 \\
0 \\
6\end{array}$ & $i^{2}$
\end{tabular} & \begin{tabular}{c|c}
0 \\
0 \\
\end{tabular} & 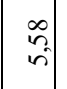 & $\begin{array}{l}\bar{n} \\
n \\
n\end{array}$ & $\underset{f}{\stackrel{\Delta}{f}}$ & 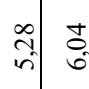 & $\left|\begin{array}{c}f \\
\vdots \\
n\end{array}\right|$ & जे & $\stackrel{?}{;}$ \\
\hline 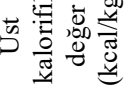 & : & 﨎 & $\begin{array}{l}\infty \\
\stackrel{0}{0} \\
\stackrel{0}{n}\end{array}$ & $\begin{array}{l}\hat{b} \\
: \\
n\end{array} \mid$ & i & 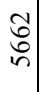 & $\overrightarrow{\bar{a}}$ & $\begin{array}{l}\hat{d} \\
\infty \\
i\end{array} \mid$ & 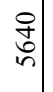 & $\begin{array}{l}\stackrel{0}{2} \\
i n\end{array}$ & 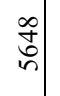 & $\begin{array}{c}\mathbb{N} \\
\text { in }\end{array}$ & ڤิ & \begin{tabular}{c|c|c}
$\hat{N}$ & $\tilde{b}$ \\
& 0 \\
$n$ & $\infty$
\end{tabular} & 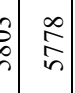 & 웅 & iे & 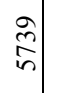 & $\begin{array}{l}\overrightarrow{0} \\
\text { in }\end{array}$ & స్రి & $\begin{array}{l}\infty \\
0 \\
0 \\
0\end{array}$ & $\overline{\widetilde{d}}$ \\
\hline 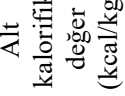 & हై & $\begin{array}{l}m \\
\vec{f}\end{array}$ & $\begin{array}{l}\infty \\
\infty \\
\stackrel{n}{n}\end{array}$ & ì & $\begin{array}{l}n \\
\stackrel{n}{n} \\
\vdots\end{array}$ & 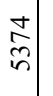 & $\begin{array}{l}\text { ôn } \\
\text { in }\end{array}$ & $\begin{array}{l}0 \\
0 \\
i \\
n\end{array} \mid$ & $\hat{n}$ & 帒 & : & f్f & है & $\begin{array}{lll}0 \\
n \\
n\end{array}$ & $\begin{array}{c}\vec{y} \\
\hat{n}\end{array}$ & $\begin{array}{l}\tilde{D} \\
i \\
i\end{array}$ & : & 离 & 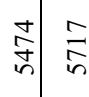 & $\begin{array}{l}\text { D. } \\
\text { in }\end{array}$ & $\begin{array}{l}\infty \\
\infty \\
i\end{array}$ & $\begin{array}{l}\infty \\
0 \\
0 \\
n\end{array}$ \\
\hline & $\sim$ & $\hat{n}$ & $\stackrel{q}{-9}$ & $\begin{array}{l}n \\
\stackrel{n}{2} \\
-9\end{array}$ & $\vec{n}$ & $\stackrel{y}{-a}$ & $\stackrel{n}{-}$ & f & 욕. & 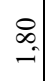 & - & $\stackrel{\leftrightarrow}{-}$ & $\stackrel{n}{-}$ & \begin{tabular}{cc}
$n$ \\
\hdashline \\
\hdashline
\end{tabular} & \begin{tabular}{l}
0 \\
\hdashline
\end{tabular} & : & $\stackrel{\infty}{\rightarrow}$ & $\stackrel{\bar{n}}{\rightarrow}$ & $\stackrel{\overbrace{}}{\rightarrow} \stackrel{?}{=}$ & $\stackrel{n}{-}$ & ? & $\stackrel{n}{-1}$ \\
\hline 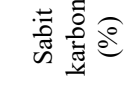 & $\hat{\tilde{q}}$ & $\begin{array}{l}\infty \\
\infty \\
\infty \\
\infty \\
\infty\end{array}$ & ڤे & $\begin{array}{l}n \\
0 \\
b\end{array}$ & $\begin{array}{c}\infty \\
0 \\
0 \\
? \\
q\end{array}$ & $\begin{array}{l}0 \\
\vdots \\
\vdots \\
n \\
m\end{array}$ & $\begin{array}{l}\text { fे } \\
\text { gे }\end{array}$ & $\begin{array}{l}\overrightarrow{5} \\
\vec{\nabla}\end{array}$ & 声 & : & $\begin{array}{l}\circ \\
\infty \\
\text { ले }\end{array}$ & $\frac{m}{\dot{q}}$ & $\begin{array}{l}\infty \\
\stackrel{1}{q} \\
\stackrel{q}{q}\end{array}$ & 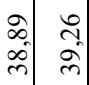 & \begin{tabular}{c|c}
0 \\
$\vdots$ \\
$\vdots$ & 0 \\
$\hat{\sigma}$
\end{tabular} & 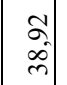 & $\begin{array}{l} \pm \\
m \\
m\end{array}$ & $\begin{array}{l}\tilde{\sigma} \\
\hat{\sigma}\end{array}$ & 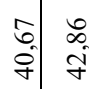 & $\begin{array}{l}\text { ते } \\
\text { jat }\end{array}$ & $\begin{array}{l}\hat{2} \\
\overrightarrow{7}\end{array}$ & $\begin{array}{l}0 \\
f \\
f\end{array}$ \\
\hline 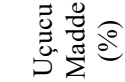 & $\underset{\infty}{\stackrel{D}{\infty}}$ & $\begin{array}{l}\text { oे. } \\
\text { के. }\end{array}$ & $\begin{array}{l}\hat{n} \\
\text { m. }\end{array}$ & $\begin{array}{l}0 \\
0 \\
0 \\
0\end{array}$ & $\begin{array}{l}0 \\
n \\
m \\
m\end{array}$ & $\begin{array}{l}\bar{b} \\
0 \\
\infty \\
\infty\end{array}$ & 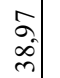 & $\begin{array}{l}\text { bे } \\
\text { m. } \\
\text { m. }\end{array}$ & $\begin{array}{l}0 \\
0 \\
\infty \\
\infty\end{array} \mid$ & $\begin{array}{c} \pm \\
\stackrel{0}{0} \\
\infty\end{array}$ & 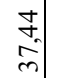 & $\begin{array}{l}a \\
\hat{m}\end{array}$ & సे & 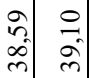 & $\begin{array}{ll}n \\
n \\
n \\
n \\
m\end{array}$ & 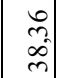 & $\begin{array}{c}\mathbb{N} \\
\infty \\
\infty \\
\infty\end{array} \mid$ & $\stackrel{8}{:}$ & ले సे సે & $\begin{array}{l}0 \\
0 \\
\dot{q}\end{array}$ & $\begin{array}{l}\infty \\
\stackrel{\infty}{0} \\
\vec{\gamma}\end{array}$ & $\begin{array}{l}\hat{q} \\
\hat{q}\end{array}$ \\
\hline & $\begin{array}{l}\stackrel{n}{\infty} \\
\infty\end{array}$ & సू. & $\begin{array}{c}\hat{\infty} \\
\infty \\
\infty\end{array}$ & $\begin{array}{l}n \\
0 \\
0\end{array}$ & $\begin{array}{l}5 \\
0 \\
a\end{array}$ & $\begin{array}{l}\hat{0} \\
\dot{a}\end{array}$ & ڤ్. & $\begin{array}{l}8 \\
8 \\
\infty\end{array}$ & $\begin{array}{l}8 \\
: \\
0\end{array}$ & n. & $\frac{m}{a}$ & $\frac{7}{a}$ & $\stackrel{2}{a}$ & $\begin{array}{cc}a \\
\text { a. } \\
\text { a }\end{array}$ & $\begin{array}{c}5 \\
0 \\
\infty \\
\infty \\
\infty\end{array}$ & 吉 & n. & $\stackrel{ \pm}{a}$ & 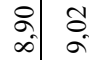 & $\begin{array}{l}2 \\
2 \\
a\end{array}$ & $\stackrel{\overbrace{}}{\stackrel{3}{\varrho}}$ & $\begin{array}{c}0 \\
\vdots \\
a\end{array}$ \\
\hline & $\stackrel{ \pm}{\stackrel{ \pm}{ \pm}}$ & 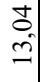 & $\stackrel{f}{q}$ & $\begin{array}{l}0 \\
0 \\
\pm\end{array}$ & $\begin{array}{l}8 \\
9\end{array}$ & $\begin{array}{l}0 \\
m \\
m \\
=\end{array}$ & $\begin{array}{l}\text { जิ } \\
\text { İ }\end{array}$ & $\begin{array}{l}8 \\
\stackrel{-}{-1}\end{array}$ & $\begin{array}{l}\stackrel{ \pm}{2} \\
\stackrel{2}{-}\end{array}$ & 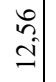 & $\begin{array}{l}0 \\
-3 \\
-1\end{array}$ & $\begin{array}{l}0 \\
\stackrel{0}{0} \\
\end{array}$ & 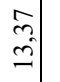 & 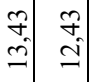 & 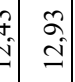 & 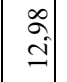 & $\begin{array}{l}\vec{b} \\
\mathbf{i}\end{array}$ & $\begin{array}{l}\infty \\
\stackrel{\infty}{\sim} \\
=\end{array}$ & 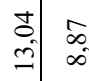 & ?े & {$\left[\begin{array}{c}0 \\
6 \\
6\end{array}\right.$} & $\vec{n}$ \\
\hline 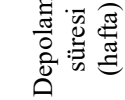 & $N$ & $\nabla$ & 6 & $\infty$ & 의 & $\simeq$ & \pm & - & $\sim$ & † & 6 & $\infty$ & & \pm \pm & \pm 0 & $N$ & $\nabla$ & 0 & $\infty \quad \varrho$ & $\simeq$ & \pm & - \\
\hline 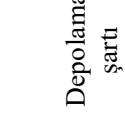 & & & & $\Xi$ & & & & & & & & & & & & & & & & & & \\
\hline
\end{tabular}


Çizelge 6. Tüm kömür örneklerine ait kendiliğinden yanma deney sonuçları

\begin{tabular}{|c|c|c|c|c|c|c|c|}
\hline & \multirow{2}{*}{\multicolumn{3}{|c|}{200 meş }} & & & \\
\hline & & & & & \multicolumn{3}{|c|}{35 meş } \\
\hline Depolama şartı & $\begin{array}{c}\text { Depolama zamanı } \\
\text { (hafta) }\end{array}$ & $\begin{array}{l}\text { Tutuşma } \\
\text { s1cakl1ğ1 } \\
\left({ }^{\circ} \mathrm{C}\right)\end{array}$ & $\begin{array}{c}\text { Ort. S1c. } \\
\text { Artışı } \\
\left({ }^{\circ} \mathrm{C} / \mathrm{dk}\right)\end{array}$ & $\begin{array}{c}\text { Yatkınlık } \\
\text { indeksi } \\
(1 / \mathrm{dk})\end{array}$ & $\begin{array}{c}\text { Tutuşma } \\
\text { s1cakliğ1 } \\
\left({ }^{\circ} \mathrm{C}\right)\end{array}$ & $\begin{array}{c}\text { Ort. Sic. } \\
\text { Artış1 } \\
\left({ }^{\circ} \mathrm{C} / \mathrm{dk}\right)\end{array}$ & $\begin{array}{c}\text { Yatkınlık } \\
\text { indeksi } \\
(1 / \mathrm{dk})\end{array}$ \\
\hline \multirow{8}{*}{$\begin{array}{l}\text { Azot tank1 } \\
\left(18^{\circ} \mathrm{C}\right)\end{array}$} & 2 & 148 & 1,46 & 9,90 & 148 & 1,29 & 8,74 \\
\hline & 4 & 146 & 1,50 & 10,32 & 154 & 1,11 & 7,21 \\
\hline & 6 & 139 & 1,61 & 11,63 & 145 & 1,17 & 8,07 \\
\hline & 8 & 142 & 1,74 & 12,29 & 146 & 1,27 & 8,76 \\
\hline & 10 & 136 & 1,69 & 12,44 & 144 & 1,26 & 8,78 \\
\hline & 12 & 143 & 1,66 & 11,65 & 147 & 1,13 & 7,71 \\
\hline & 14 & 144 & 1,92 & 13,40 & 142 & 1,18 & 8,32 \\
\hline & 16 & 141 & 1,69 & 12,00 & 145 & 1,19 & 8,24 \\
\hline \multirow{8}{*}{$\begin{array}{c}\text { Derin } \\
\text { dondurucu } \\
\left(-25^{\circ} \mathrm{C}\right)\end{array}$} & 2 & 149 & 1,42 & 9,58 & 147 & 1,15 & 7,87 \\
\hline & 4 & 147 & 1,41 & 9,59 & 141 & 1,27 & 9,07 \\
\hline & 6 & 143 & 1,48 & 10,39 & 145 & 1,25 & 8,62 \\
\hline & 8 & 140 & 1,44 & 10,33 & 152 & 1,23 & 8,13 \\
\hline & 10 & 138 & 1,59 & 11,55 & 143 & 1,26 & 8,84 \\
\hline & 12 & 144 & 1,54 & 10,75 & 150 & 1,34 & 8,94 \\
\hline & 14 & 145 & 1,64 & 11,32 & 146 & 1,30 & 8,96 \\
\hline & 16 & 142 & 1,69 & 11,91 & 150 & 1,29 & 8,62 \\
\hline \multirow{8}{*}{$\begin{array}{c}\text { Firın } \\
\left(30^{\circ} \mathrm{C}\right)\end{array}$} & 2 & 140 & 1,37 & 9,82 & 151 & 1,1 & 7,28 \\
\hline & 4 & 135 & 1,37 & 11,64 & 149 & 1,17 & 7,85 \\
\hline & 6 & 139 & 1,69 & 12,17 & 144 & 1,32 & 9,20 \\
\hline & 8 & 144 & 1,83 & 12,73 & 143 & 1,46 & 10,25 \\
\hline & 10 & 136 & 1,89 & 13,94 & 140 & 1,54 & 11,06 \\
\hline & 12 & 138 & 2,00 & 14,49 & 145 & 1,71 & 11,85 \\
\hline & 14 & 139 & 2,07 & 14,93 & 142 & 1,77 & 12,49 \\
\hline & 16 & 134 & 2,03 & 15,20 & 144 & 1,83 & 12,73 \\
\hline
\end{tabular}

\section{BULGULAR VE TARTIŞMA}

Depolama süresi boyunca kömürlerin kimyasal analiz değerlerinde özellikle sıcaklığa bağlı olarak değişimler yaşandığı görülmektedir. Kömürdeki nem oranının artması kendiliğinden yanma indeksinin azalmasına neden olmuştur. Nem içeriği yüksek kömürlerin söz konusu grafikten hareketle kendiliğinden yanma açısından daha az risk taşıdığı rahatlıkla söylenebilmektedir (Şekil 2).

Genel olarak kömür örneklerinin kül oranlarında ciddi değişimler yaşanmasa da, sadece etüv de depo edilen ince tane için belirgin farklılıkların olduğu ifade edilebilmektedir. Kömürde meydana gelen oksidasyonun etkileri, kül yüzdelerinde meydana gelen artıştan açıkça görülebilmektedir. Özellikle ince taneli örnekler iri taneye oranla fark edilir biçimde yüksek değerler almıştır (Şekil 3). Şekil 4'te uçucu madde miktarlarındaki değişimin kendiliğinden yanma risk indeksi üzerindeki etkileri gösterilmektedir. Depolama süresi boyunca uçucu madde yüzdelerinde çok net değişimlerin olduğunu söylemek zordur. Dağınık bir görüntü sergilemesine rağmen özellikle etüv de depo edilen örneklerde uçucu madde ile yanma risk indeksi açısından doğru orantılı bir ilişkinin olduğu söylenebilmektedir. 


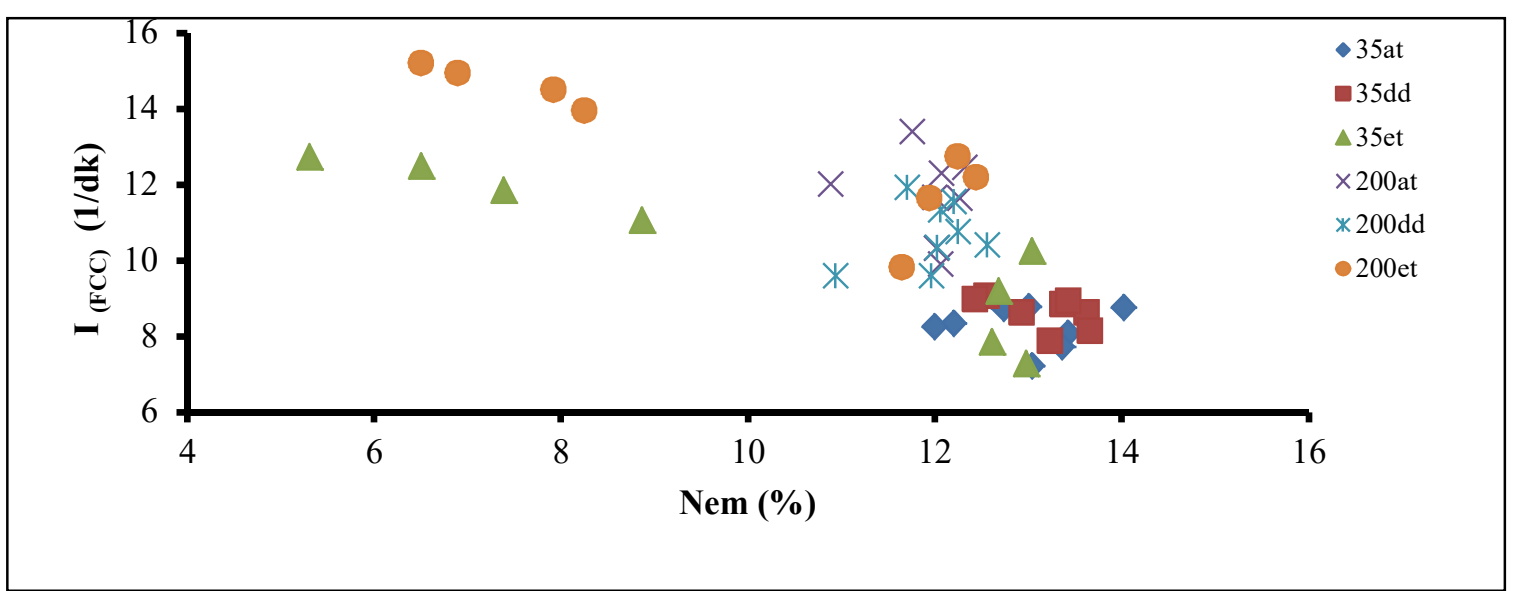

Şekil 2. Tüm kömür örnekleri için 16 haftalık yatkınlık indeksi - nem ilişkisi

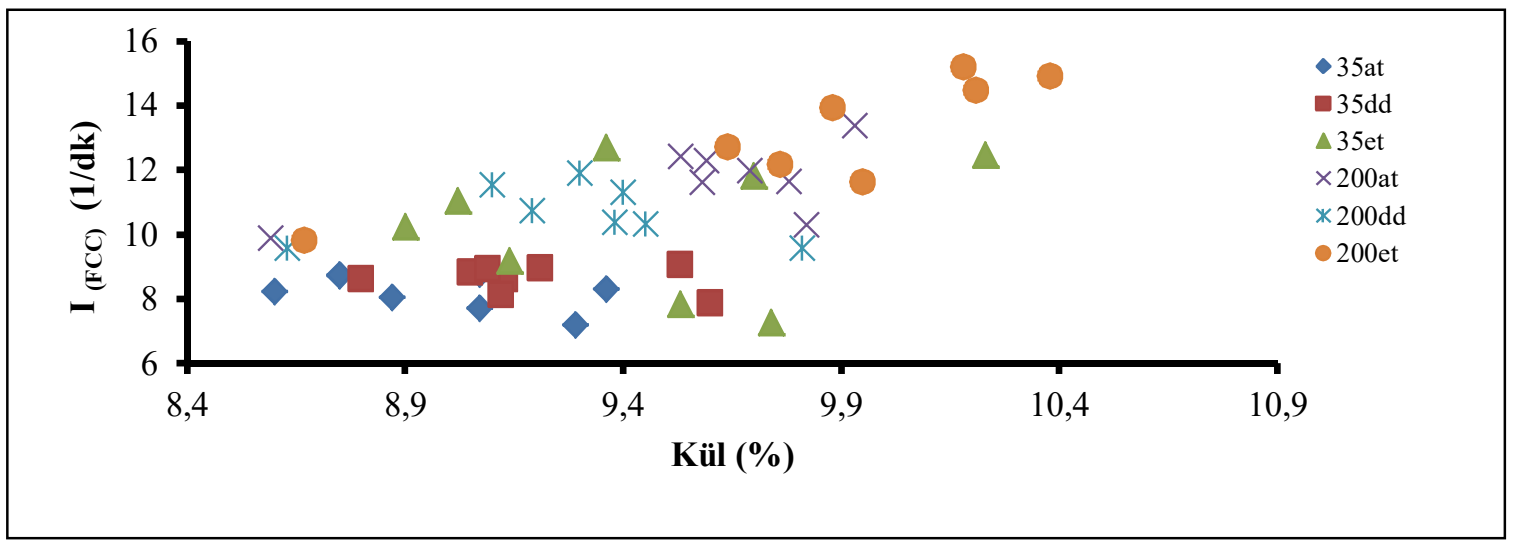

Şekil 3. Tüm kömür örnekleri için 16 haftalık yatkınlık indeksi - kül ilişkisi

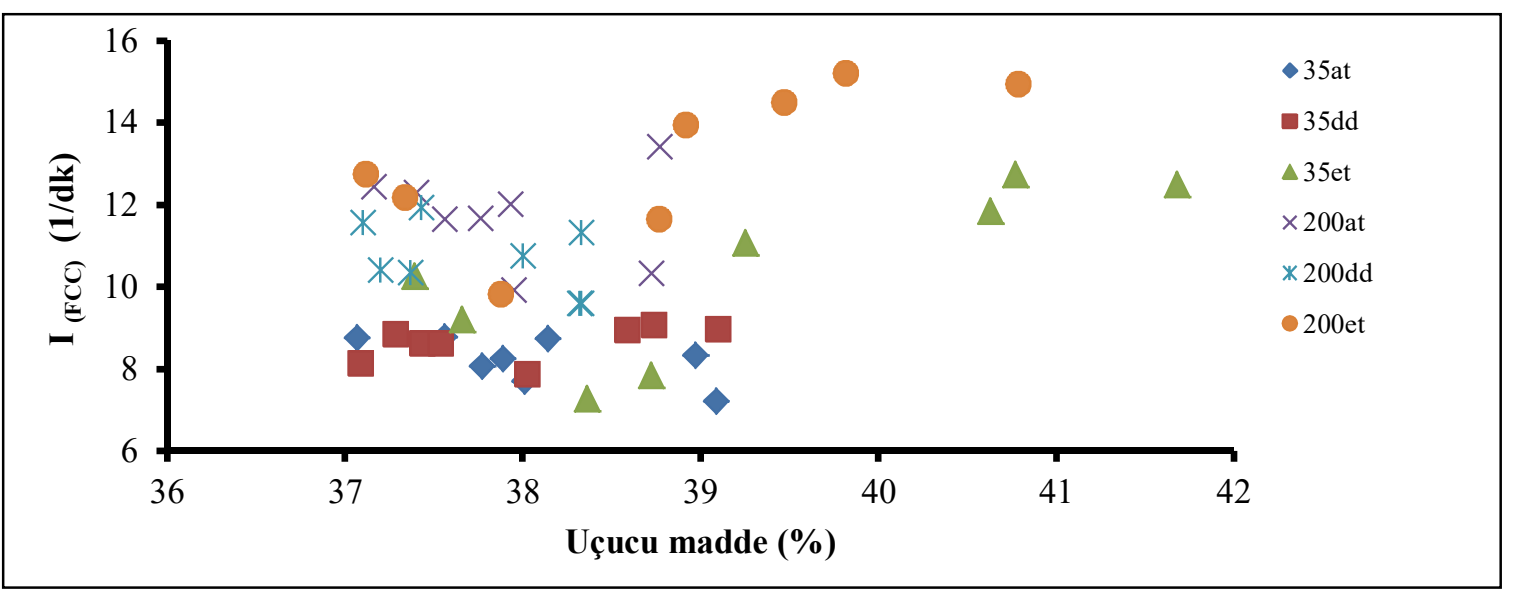

Şekil 4. Tüm kömür örnekleri için 16 haftalık yatkınlık indeksi- uçucu madde ilişkisi 
Kömürlerin sabit karbon miktarlarında depolama süresince genel olarak bir artış meydana gelmiştir. Yapılan değerlendirmelerde, bu artışın izafi bir artış olduğu tespit edilmiş ve kömürdeki nem miktarının azalması ile birlikte yapılan hesaplamalarda karbon değerlerinde yükselmelerin yaşandığı düşünülmektedir (Şekil 5). Depo sürecinin başlangıcından tamamlanmasına kadar hem alt hem de üst kalorifik değer açısından bakıldığında etüv örneğinde artışların olduğu görülmektedir (Şekil 6). Var olan kalorifik değişimlerin kömür oksidasyonundan ziyade kömürdeki nem içeriğinden etkilendiğini söylemek mümkündür. Özellikle kömürde başlangıçta yaklaşık \%11-12 olarak belirlenen nem değerleri, depolama sürecinin sonlarına doğru yaklaşık \%5-6 gibi değerlere gerilemiştir.

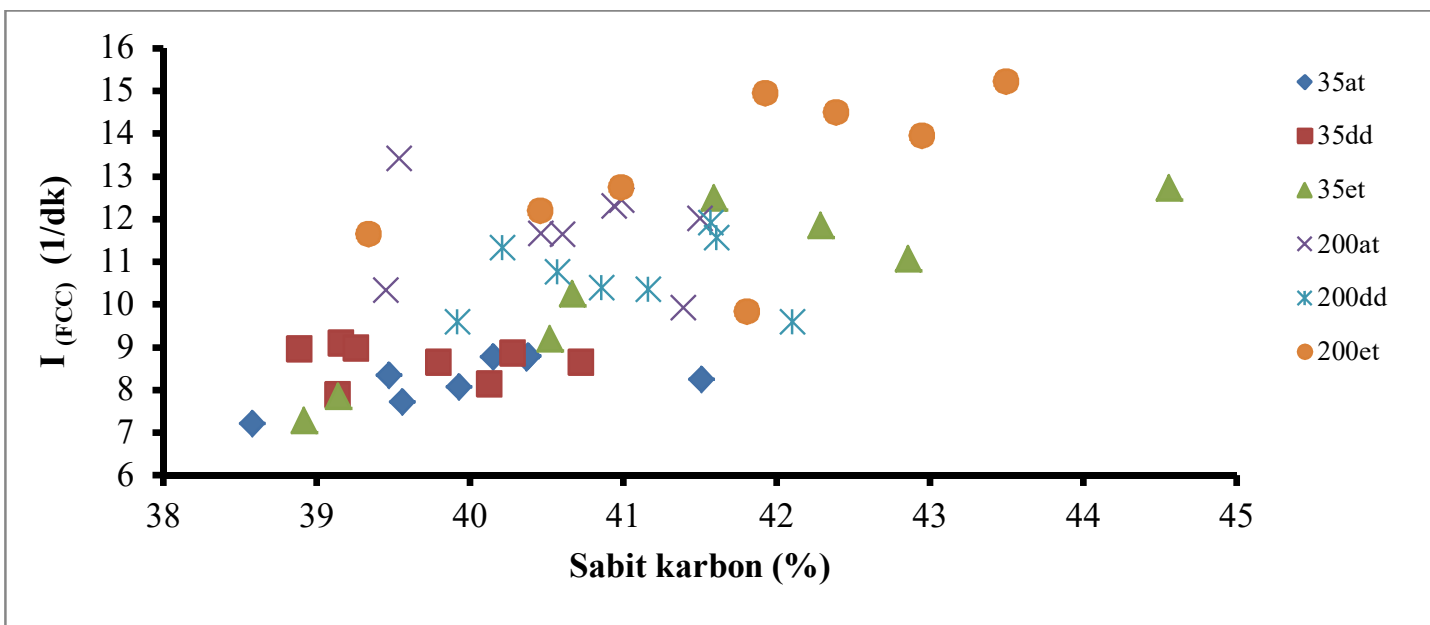

Şekil 5. Tüm kömür örnekleri için 16 haftalık yatkınlık indeksi - sabit karbon ilişkisi

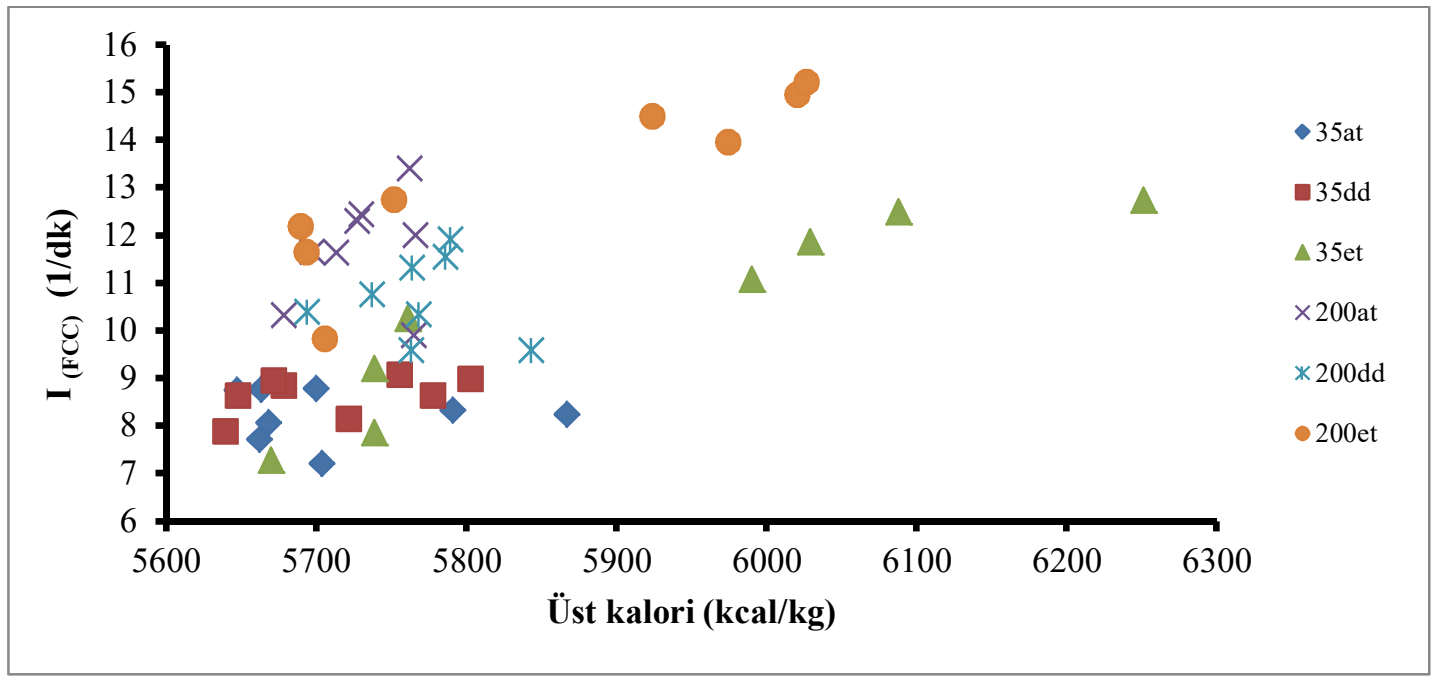

Şekil 6. Tüm kömür örnekleri için 16 haftalık yatkınlık indeksi - üst kalori ilişkisi 


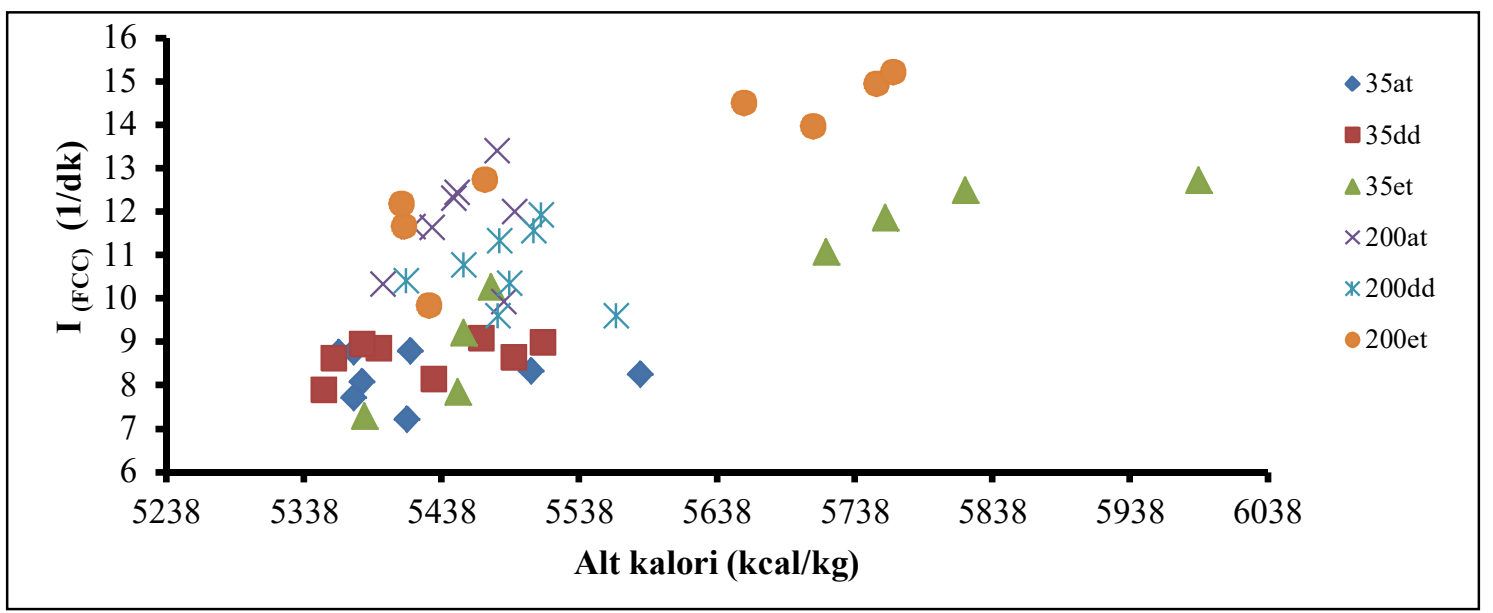

Şekil 7. Tüm kömür örnekleri için 16 haftalık yatkınlık indeksi - alt kalori ilişkisi

Alt kalori değerlerindeki değişimlerin gösterildiği grafikler incelendiğinde (Şekil 7), azot tankı ve derin dondurucu örnekleri ile kapalı depo şartlarında saklanan etüv örnekleri için değerlerin birbirine çok yakın olduğu gözükmektedir. Kömürler açık olarak depo edilmeye başlandıktan sonraki süreçte, etüv örneklerine ait numunelerde belirgin bir artışın meydana geldiği görülmektedir. Söz konusu kömür örneklerinin elementel analizleri ile kendiliğinden yanma yatkınlıkları arasında ilişkiler Şekil 8-12 'de gösterilmiştir. Grafikler incelendiğinde, anlamlı değişimlerin sadece karbon ve oksijen yüzdelerinde olduğunu söylemek mümkündür. Yapılan analizlerde azot tankı ve derin dondurucu numunelerinde depolama sürecinin başlangıcından itibaren oksijen yüzdelerinde az miktarda değişime rastlanılmıştır. Özellikle 8. ve 10. haftalar arasındaki süreç diliminde oksijen yüzdelerinde önemli düşüşler meydana gelmiştir. $\mathrm{Bu}$ süreçte kömür bünyesindeki oksijenin aktif hale geçerek kömür içerisindeki mikro gözeneklere adsorbe olduğu anlaşılmaktadır. Süreç içerisinde oksijen yüzdesinde meydana gelen çarpıcı düşüşlerin kaynağının özellikle oksijenin kömür bünyesindeki karbon ve hidrojen ile bağ yapması sonucu oluşan katı ürünlerden ileri geldiği düşünülmektedir. Oluşan $\mathrm{CO}, \mathrm{CO}_{2}$, karbonil ve karboksil türündeki bileșimlerin buna bağlı olarak ta karbon miktarını arttırdığı tahmin edilmektedir.

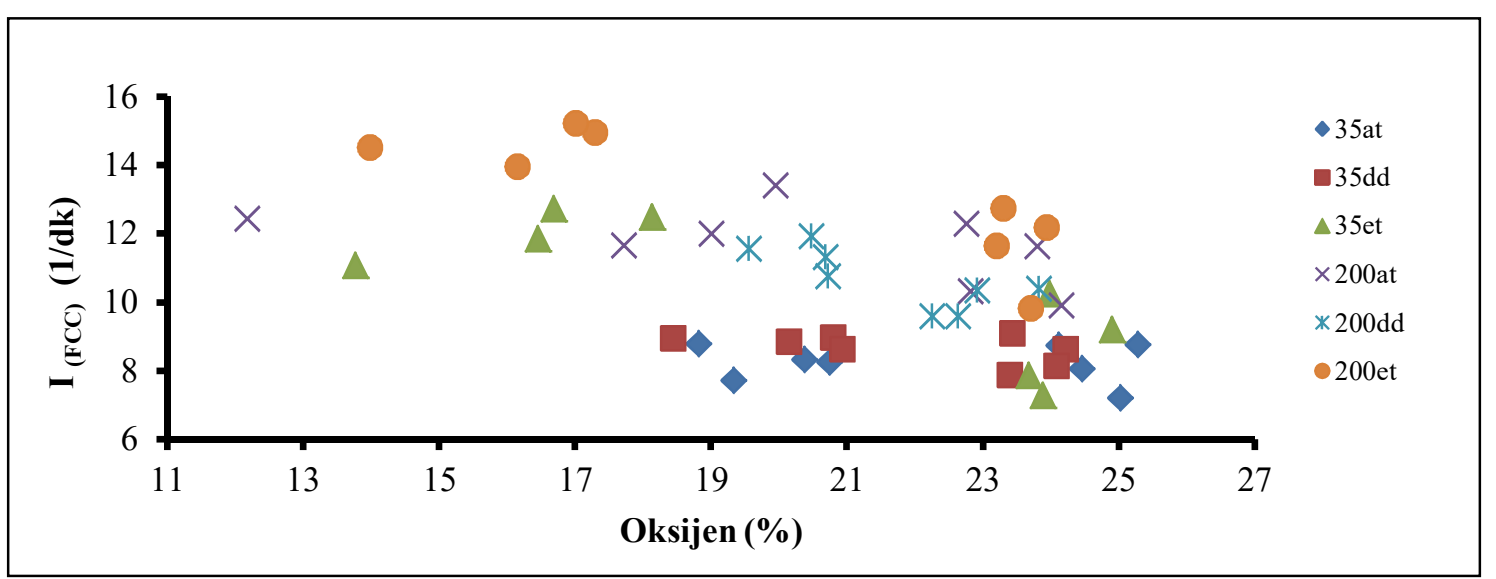

Şekil 8. Tüm kömür örnekleri için 16 haftalık yatkınlık indeksi - oksijen ilişkisi 


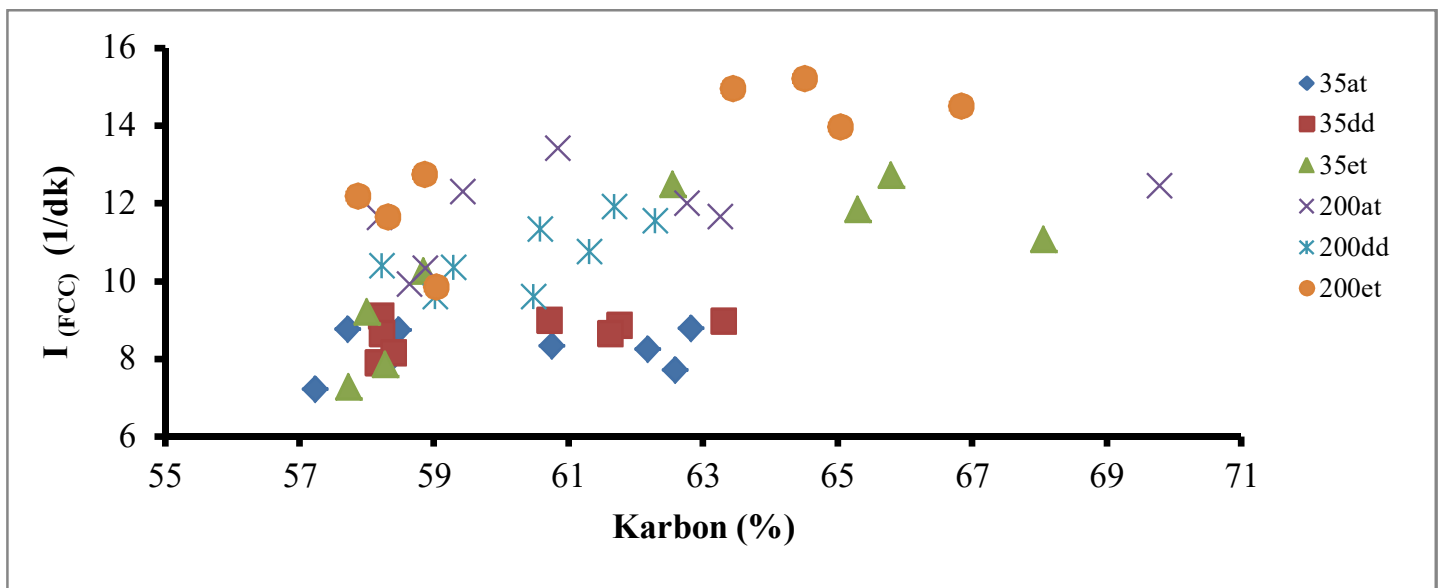

Şekil 9. Tüm kömür örnekleri için 16 haftalık yatkınlık indeksi - karbon ilişkisi

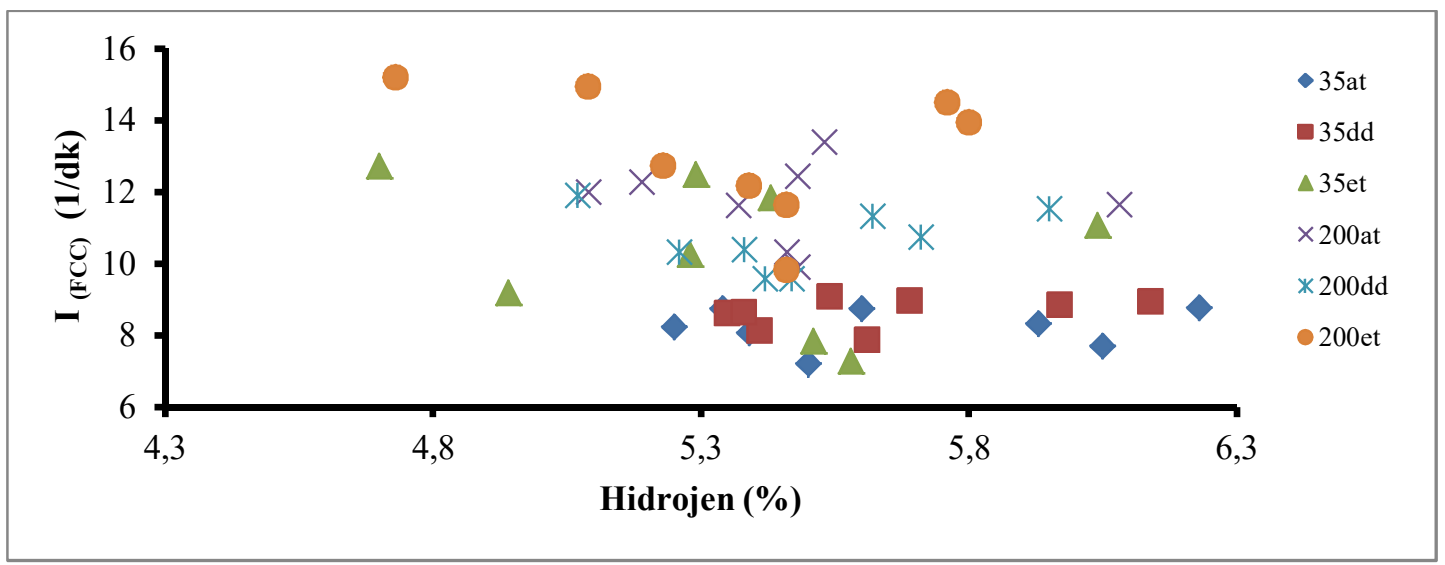

Şekil 10. Tüm kömür örnekleri için 16 haftalık yatkınlık indeksi - hidrojen ilişkisi

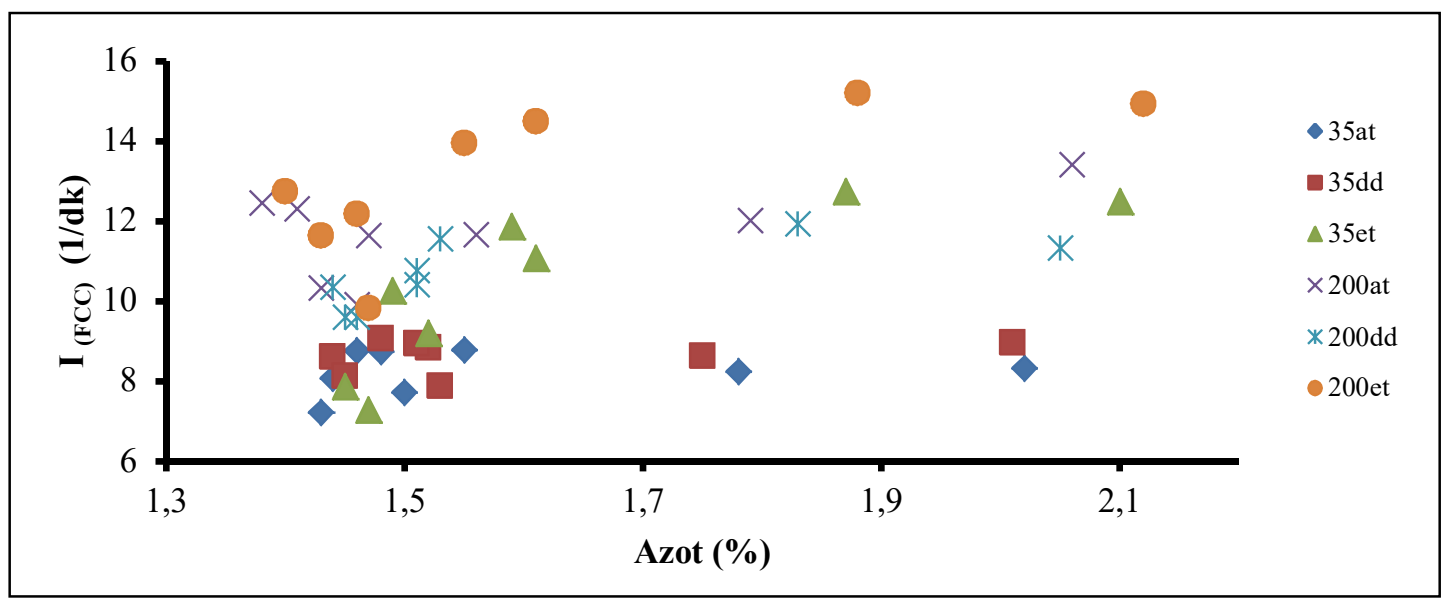

Şekil 11. Tüm kömür örnekleri için 16 haftalık yatkınlık indeksi - azot ilişkisi 


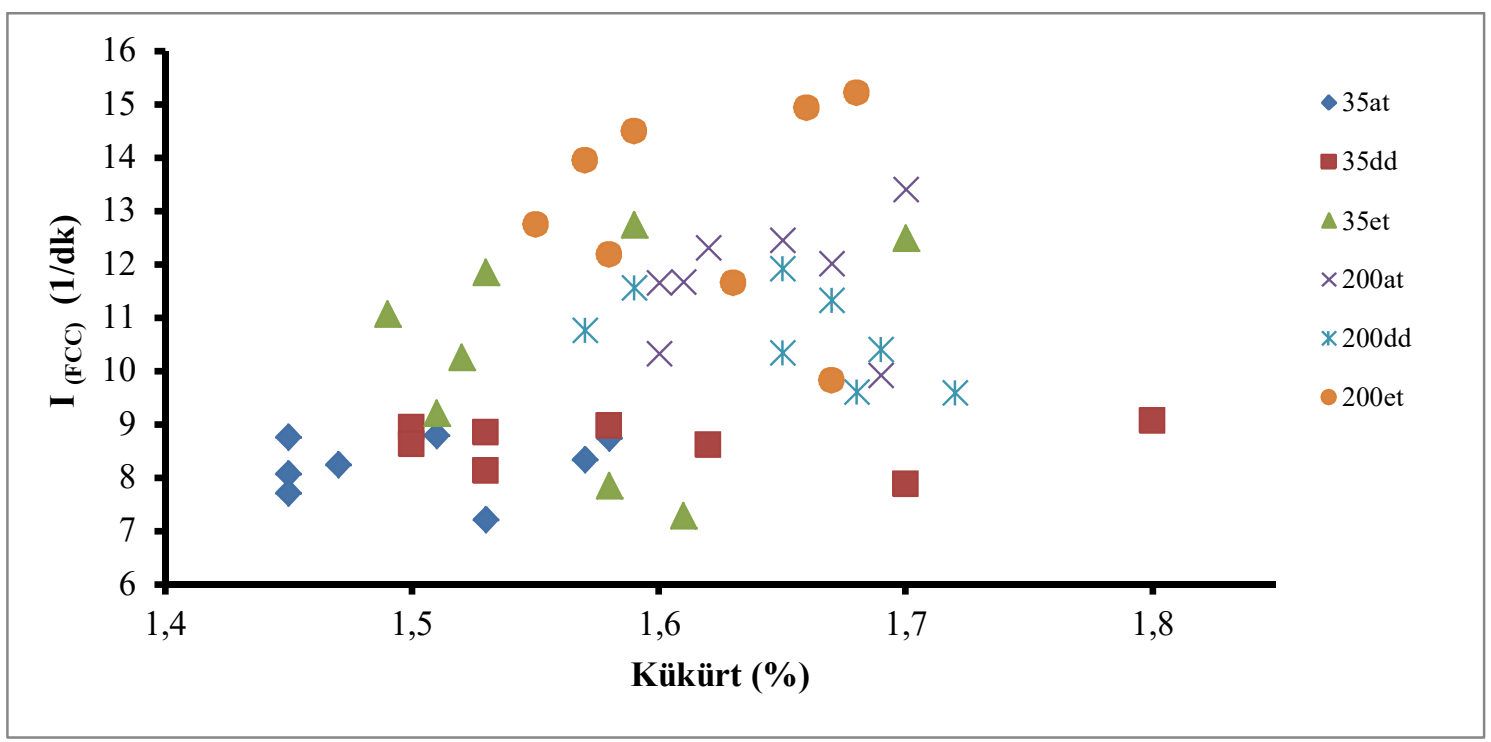

Şekil 12. Tüm kömür örnekleri için 16 haftalık yatkınlık indeksi - kükürt ilişkisi

\section{SONUÇLAR}

Yapılan bu çalışma ile kömüre ait kısa ve elementel analiz sonuçları ile kömürün kendiliğinden yanma yatkınlığı arasındaki ilişki incelenmiştir. Buna göre özellikle kömürün neminin kendiliğinden yanma davranışında ve oksidasyonda etkin bir rol üstlendiği gözlenmiştir. Artan nem içeriğinin yatkınlık indeksini azalttığı görülmüştür. Kimyasal analiz sonuçlarında dikkat çekici en önemli noktanın, kömürdeki sabit karbon yüzdesinin süreç sonunda artması olarak söylenebilir. Geçmiş dönemlerde, oksidasyon sonucu kömürdeki karbon yüzdelerinde azalmanın meydana geldiği araştırmacılar tarafindan ifade edilmiştir [10]. Bunun sebebinin, ilerleyen süreç ile birlikte kömürdeki nemin azalması ve bu azalmanın da hesaplamalarda \% karbon değerlerinin yükselmesinden kaynaklandığı düşünülmektedir. Ayrıca oksijen yüzdesi değerlerinde de tam tersine bir azalma söz konusu olmuştur. $\mathrm{Bu}$ azalmaya kömür ile oksijenin reaksiyona girmesi sonucu oluşan gaz ürünlerin $\left(\mathrm{CO}_{2}\right.$ ve $\left.\mathrm{CO}\right)$ neden olduğu tahmin edilmektedir. Kömürün külü ve uçucu maddesinin ise sürece direk etkisinin olduğunu söylemek zordur. Genel olarak yatkınlık indeksi değerleri ile uçucu madde yüzdesi arasında doğru orantılı bir ilişki olduğu ifade edilebilmektedir. Depolama süresi içerisinde kömürlerde oksidasyonun meydana geldiği ve bu durumun kül değerlerinde artışa neden olduğu da görülmüştür. Kömürün hem alt kalori hem de üst kalori miktarında ise etüv numunesi haricinde pek fazla bir değişim gözlenmezken, etüvde depo edilen örneklerde azalan nem ile birlikte kalori değerlerinde artış meydana gelmiştir. Bunların haricinde kömürdeki hidrojen (\%), kükürt (\%), azot (\%) gibi diğer elementel analiz verilerinde süreç boyunca çok fazla bir değişim yaşanmazken, söz konusu verilerin kömürün yanma değerleri üzerinde çarpıcı bir etkisinin olduğu da söylenememektedir.

\section{KAYNAKLAR}

1. Uludağ, S., 2001. Assessing Spontaneous Combustion Risk in South African Coal Mines Using a GIS Tool, M.Sc Dissertation, University of Witwatersrand, South Africa.

2. Giroux, L., Kolijn, C.J., Pichler, F.S., 2006. Storage of Small Samples of Coking Coal for Thermal Rheological Tests, Fuel Processing Technology, 87, 547-561

3. Küçükbayrak, S., Haykırı-Açma, H., ErsoyMeriçboyu, A., Yaman, S., 2001. Effect of Lignite Properties on Reactivity of Lignite, 
Energy Conversion and Management, 42, 613626.

4. Qi, X., Wang, D., Milke, J.A., Zhong, X., 2011. Crossing Point Temperature of Coal, Mining Science and Technology, 21, 255 -260.

5. Kadioglu, Y., Varamaz, M., 2003. The effect of Moisture Content and Air-Drying on Spontaneous Combustion Characteristics of two Turkish Lignites, Fuel, 82, 1685 - 1693.

6. Nugroho, Y.S., McIntosh, A.C., Gibbs, B.M., 2000. Low temperature Oxidation of Single and Blended Coals, Fuel, 79, 1951-1961.

7. Küçük, A., Kadığlu, Y., Gülaboğlu, M.Ş., 2003. A Study of Spontaneous Combustion Characteristics of a Turkish Lignite: Particle Size, Moisture of Coal, Humidity of Air, Combustion and Flame, 133, 255-261.

8. Beamish, B., Arısoy, A., 2008. Effect of Mineral Matter on Coal Self-Heating Rate, Fuel, 87, 125-130.

9. Ören, Ö., 2015. Farklı Saklama Koşullarında Depo Edilen Kömürlerin Kendiliğinden Yanma Davranışlarının Termogravimetrik ve Yüzey Adsorpsiyon Mekanizmaları Açısından İncelenmesi-Tunçbilek Linyitleri Örneği, Doktora Tezi, Dumlupınar Üniversitesi, 336 p.

10. Liotta R., Brons G., Isaacs J., 1983. Oxidative Weathering of Illinois No. 6 coal, Fuel, 62, 781-791. 
